\section{Hanxu: A New Iris sanguinea Cultivar}

\section{Zong-zhe Wan ${ }^{1}$, Ya-nan $\mathrm{Li}^{1}$, Xin-yu Qi ${ }^{1}$, Dan Wang ${ }^{1}$, and Ling Wang ${ }^{2}$ College of Landscape Architecture, Northeast Forestry University, Harbin, China 150040}

Additional index words. ornamental, flower, erect plant stature
The genus Iris belongs to the Iridaceae family, which is well known throughout the world for its diverse color and unique flower shape. In China, Iris sanguinea, one species species. It is a perennial herb with a wide distribution in the Heilongjiang, Liaoning, and Jilin provinces of northeast China (Zhao et al., 2000). It is a valuable ornamental landscape plant because of its large, showy flower with a distinctive flower pattern. It is also drought tolerant and resistant to pollution. It exhibits rapid propagation, strong resistance to diseases and pests, and produces an outstanding flower suitable for cut-flower production. To date, there are $\approx 60,000$ Iris cultivars worldwide (Luo et al., 2016). Recently, I. sanguinea breeders have developed and released new cultivars with new color variations. Primarily, these recently released cultivars involved new flower colors. These new cultivars include 'Zidie' with a purple flower (C60 M90) (Dong et al., 2014), 'Beautiful Lotus' with a pinkish purple violet flower (NCS S3030-R60B) (Wang et al., 2016), and 'Forest Fairy' with a light violet (RHS 85C) flower (Kuwantai et al., 2018). These new cultivars were selected and released for their flower color rather than a new and unique change in the structure of the flower or plant. In 2012, a new I. sanguinea cultivar, Hanxu, was identified as having a unique plant and flower structure.

\section{Origin}

The new I. sanguinea cultivar Hanxu was selected from an open-pollinated progeny population of $I$. sanguinea at the Mao-ErShan experimental nursery of Northeast Forestry University, Harbin, China. The seeds of I. sanguinea were collected from Shenyang Botanical Garden in 2003. Open-pollinated seeds were harvested in Fall 2009 and planted in Spring 2010. In 2012, a unique progeny (NEFU 2012-7) was observed in the mixed population. The cultivar is unique with respect to flower and plant structure with two

Received for publication 5 Mar. 2019. Accepted for publication 27 Mar. 2019.

This study was supported by the National Natural Science Foundation of China (No. 31670344) and the Fundamental Research Funds for the Central Universities (No. 2572016EAJ6).

${ }^{1}$ Joint first authors and these authors contributed equally to this work

${ }^{2}$ Corresponding author. E-mail: wanglinghlj@ 126.com. of Iris, is a typical cold-region ornamental flowers on top of a single scape that is wrapped by one bract. Further, although all scapes are tall with a similar height, the scapes are slightly lower than the cultivar's erect leaves. The tillers of this plant were vegetatively propagated and planted in a new research plot. The plant's field performance was observed from 2015 to 2017, and data were collected for statistical analysis. The morphological traits of all the propagated plants were stable and consistent. In 2017, this cultivar was named Hanxu (Chinese for "veiled") and officially authorized by the American Iris Society with an accession No.17-0987.

\section{Description}

The new cultivar Hanxu and the original $I$. sanguinea were planted and randomly arranged in a field experiment with three replications in a nursery of Northeast Forestry University, Harbin, China. A total of 30 plants (10 plants per replication) were randomly selected for data collection. The following morphological traits were collected from 2015 to 2017 during the flowering period: plant height, leaf length, scape length, leaf length/scape length, flower diameter, inner perianth length/width, outer perianth length, outer perianth width, outer perianth length/width, and flower period. All colors were based on the Royal Horticultural Society (2007) Color Chart and designated as RHS numbers. The data were analyzed using SPSS 22.0 software (IBM, Armonk, New York, NY) with Student's $t$ test.

The characteristics and traits of $I$. sanguinea 'Hanxu' and I. sanguinea are presented in Tables 1 and 2. 'Hanxu' has a compact, moderately tight, erect plant structure, compared with the less compact, looser, and moderately erect plant structure of I. sanguinea (Fig. 1). 'Hanxu' leaves are erect with relatively uniform plant height up to $92 \mathrm{~cm}$. 'Hanxu' plant height is equivalent to its leaf length. The flowers are located below the upper level of the leaves and "hidden" in the vertical leaf foliage. 'Hanxu' plant structure is easily differentiated from the original I. sanguinea (Fig. 1). The native $I$. sanguinea leaves are shorter $(56 \mathrm{~cm})$ and less erect than those of the new cultivar $(92 \mathrm{~cm})$. The native $I$. sanguinea also has shorter scapes $(74 \mathrm{~cm})$ than 'Hanxu' (79 cm). The anther color of 'Hanxu' is pure light blue violet (RHS 93B), in contrast to the blue violet color (RHS N92C) of I. sanguinea. During flowering, 'Hanxu' produces two flowers within a single bract. The inner perianths of 'Hanxu' and I. sanguinea are erect. The length and width of 'Hanxu's' inner perianths are 4.6 and $2.7 \mathrm{~cm}$, respectively, compared with I. sanguinea's 4.4 and $1.4 \mathrm{~cm}$. The outer perianths of the flowers inner perianth length, inner perianth width,

Table 1. A comparison of the plant morphology of Iris sanguinea 'Hanxu' and wild I. sanguinea.

\begin{tabular}{lll}
\hline Descriptor & I. sanguinea 'Hanxu' & \multicolumn{1}{c}{ I. sanguinea } \\
\hline Plant type & Erect & Less erect/drooping \\
Leaf & Erect & Erect/pendulous \\
Scape & Lower than the leaves & Higher than the leaves \\
Flower color & RHS 93B & RHS N92C \\
Flower form & Compact & Incompact \\
Flower number & 2 in one bract & $1-2$ in one bract \\
Blossoming time & Overlapping & Continuous \\
Inner perianth & Erect & Erect \\
Outer perianth & Slightly drooping & Completely drooping \\
\hline
\end{tabular}

${ }^{\mathrm{z}}$ Color determination is based on comparison with RHS Color Chart.

Table 2. Comparisons of Iris sanguinea 'Hanxu' plant characteristics and wild I. sanguinea grown in the field during flowering period from 2015 to 2017 in Harbin, China.

\begin{tabular}{lcr}
\hline Traits & I. sanguinea 'Hanxu' & I. sanguinea \\
\hline Plant height $(\mathrm{cm})$ & $92.04 \pm 0.57 \mathrm{a}^{z}$ & $63.22 \pm 0.60 \mathrm{~b}$ \\
Leaf length $(\mathrm{cm})$ & $92.04 \pm 0.57 \mathrm{a}$ & $55.72 \pm 0.33 \mathrm{~b}$ \\
Scape length $(\mathrm{cm})$ & $79.30 \pm 0.62 \mathrm{a}$ & $74.10 \pm 0.35 \mathrm{~b}$ \\
Leaf/scape length & $1.16 \pm 0.01 \mathrm{a}$ & $0.75 \pm 0.01 \mathrm{~b}$ \\
Flower diameter $(\mathrm{cm})$ & $9.46 \pm 0.05 \mathrm{a}$ & $6.40 \pm 0.04 \mathrm{~b}$ \\
Inner perianth length $(\mathrm{cm})$ & $4.64 \pm 0.04 \mathrm{a}$ & $4.38 \pm 0.05 \mathrm{a}$ \\
Inner perianth width $(\mathrm{cm})$ & $2.67 \pm 0.04 \mathrm{a}$ & $1.39 \pm 0.02 \mathrm{~b}$ \\
Inner perianth length/width & $1.75 \pm 0.03 \mathrm{~b}$ & $3.17 \pm 0.04 \mathrm{a}$ \\
Outer perianth length $(\mathrm{cm})$ & $5.67 \pm 0.05 \mathrm{a}$ & $5.56 \pm 0.05 \mathrm{~b}$ \\
Outer perianth width $(\mathrm{cm})$ & $4.28 \pm 0.03 \mathrm{a}$ & $2.46 \pm 0.04 \mathrm{~b}$ \\
Outer perianth length/width & $1.33 \pm 0.01 \mathrm{~b}$ & $2.28 \pm 0.02 \mathrm{a}$ \\
Flower period & 2 June to 28 June & 5 June to $25 \mathrm{June}$ \\
\hline
\end{tabular}

${ }^{\mathrm{z}}$ Different letters indicate significant differences among the treatments according to Student's $t$ test $(P<$ $0.05)$. 


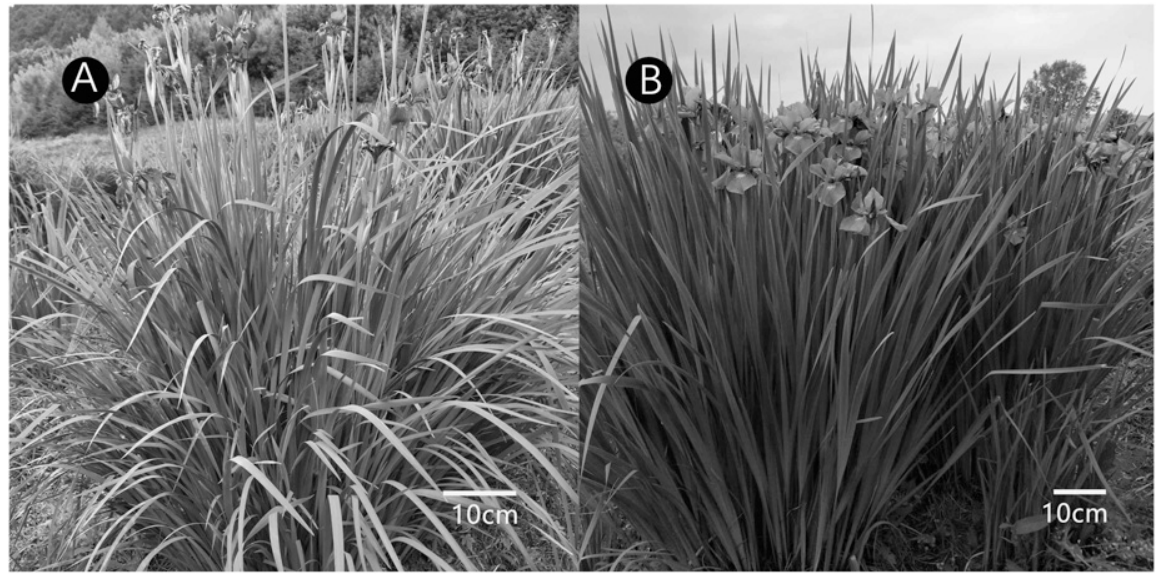

Fig. 1. Comparisons of plants of wild I. sanguinea (A) and cultivar I. sanguinea 'Hanxu' (B). 'Hanxu' is erect with flowers beneath the leaves, compared with I. sanguinea.

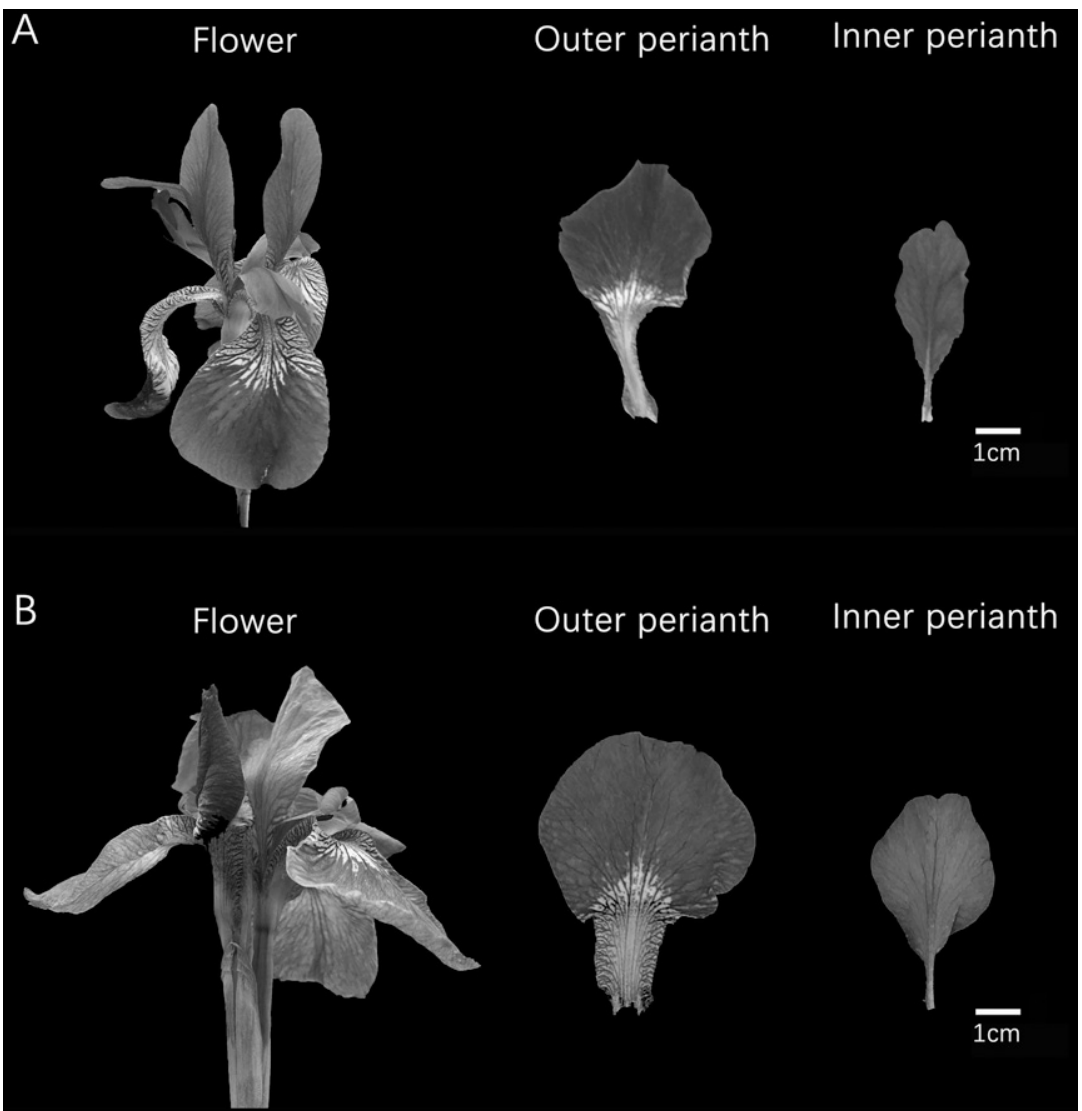

Fig. 2. Comparisons of flower and perianths of wild I. sanguinea (A) and cultivar I. sanguinea 'Hanxu' (B). Hanxu' has larger flowers and perianths with a violet blue color.

are different; 'Hanxu' is $5.7 \mathrm{~cm}$ in length and slightly drooping, whereas, I. sanguinea is $5.6 \mathrm{~cm}$ in length and completely drooping.
The outer perianths width of 'Hanxu' $(4.3 \mathrm{~cm})$ are 1.7 times larger than that of $I$. sanguinea $(2.5 \mathrm{~cm})$. The flower diameter of 'Hanxu' is $9.5 \mathrm{~cm}$, which is significantly larger than that of $I$. sanguinea $(6.4 \mathrm{~cm})$ (Fig. 2). 'Hanxu' flowers blossom from June 2 to June 28 , 1 week longer than I. sanguinea (June 5 to June 25) (Table 2).

In summary, I. sanguinea 'Hanxu' has an erect compact plant structure with larger violet-blue (RHS 93B) flowers that are located lower than its erect leaves and a longer flowering period than the native I. sanguinea.

\section{Cultivation Techniques}

'Hanxu' is suitable for growing in moist soils under abundant sunshine. It is recommended that division propagation should be conducted in the spring, summer, and/or early fall using the ramets. Individual plants should be planted $30 \mathrm{~cm}$ apart in the field under regular irrigation followed by weed control to assist in the proper establishment of the new plants.

\section{Recommendation}

I. sanguinea 'Hanxu' is an ideal compact flowering plant for garden landscapes. Its flowers and leaves are also suitable for flower arrangements.

\section{Availability}

Information about plant material and research of 'Hanxu' can be obtained from Dr. Ling Wang (wanglinghlj@126.com) at the College of Landscape Architecture, Northeast Forestry University, Harbin, China.

\section{Literature Cited}

Dong, R., H.X. Zhao, D.F. Gu, and W.Q. Wang. 2014. A new Iris sanguinea cultivar 'Zidie'. Acta Hort. Sin. 41(3):607-608.

Luo, G.J., Y.E. Xiao, W.J. Xu, X.Y. Bi, H. Li, X.Y. Lian, F.Y. Yu, Y. Zheng, and J.J. Lei. 2016. Studies on morphological variations and karyotypes of three Iris dichotoma accessions with different flower colors. J. Plant Genet. Resources 17(2):266-272.

Kuwantai, A., Y.J. Liu, Z.Z. Wan, H.Y. Liu, and L. Wang. 2018. 'Forest Fairy': A new Iris sanguinea cultivar. HortScience 53:1222-1223.

Royal Horticultural Society. 2007. Royal Horticultural Society Color Chart. Royal Hort. Soc., London, UK.

Wang, L., D.M. Xia, Y.N. Li, H.M. Peng, H.L. Chen, and L.J. Fan. 2016. A new Iris sanguinea cultivar 'Beautiful Lotus'. Acta Hort. Sin. 43(8):1629-1630.

Zhao, Y.T., J.N. Henry, and M. Brian. 2000. Iridaceae, p. 301. In: Z.Y. Wu, P.H. Raven, and D.Y. Hong (eds.). Flora of China, Vol. 24 Sci. Press \& Missouri Botanical Garden, Beijing, China. 